\title{
Postprandial Metabolism and Physical Activity in Asians: A Narrative Review
}

\section{(요 $\Theta \Theta$}

\author{
Authors

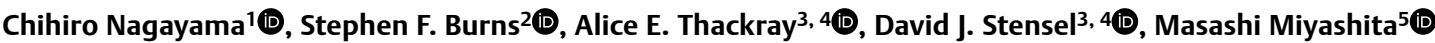

Affiliations

1 Graduate School of Sport Sciences, Waseda University, Tokorozawa, Japan

2 Department of Physical Education and Sports Science, National Institute of Education, Nanyang Technological University, Singapore

3 National Centre for Sport and Exercise Medicine, School of Sport Exercise and Health Sciences, Loughborough University, Loughborough, United Kingdom of Great Britain and Northern Ireland

4 National Institute for Health Research (NIHR) Leicester Biomedical Research Centre, University Hospitals of Leicester NHS Trust and University of Leicester, Leicester, United Kingdom of Great Britain and Northern Ireland

5 Faculty of Sport Sciences, Waseda University, Tokorozawa, Japan

Key words

postprandial triglyceridemia, postprandial glycemia, ethnicity, cardiovascular disease risk factors

accepted 15.04.2021

published online $\quad 09.08 .2021$

Bibliography

Int J Sports Med 2021; 42: 953-966

DOI 10.1055/a-1493-2948

ISSN $0172-4622$

(C) 2021. The Author(s).

This is an open access article published by Thieme under the terms of the Creative Commons Attribution-NonDerivative-NonCommercial-License, permitting copying and reproduction so long as the original work is given appropriate credit. Contents may not be used for commecial purposes, or adapted, remixed, transformed or built upon. (https://creativecommons. org/licenses/by-nc-nd/4.0/)

Georg Thieme Verlag KG, Rüdigerstraße 14,

70469 Stuttgart, Germany
Correspondence

Masashi Miyashita

Faculty of Sport Sciences, Waseda University,

2-579-15 Mikajima

359-1192 Tokorozawa

Japan

Tel.: + 81-4-2947-6774, Fax : +81-4-2947-6774

m.miyashita@waseda.jp

\section{ABSTRACT}

The widespread benefits of physical activity in enhancing health and lowering the risk of non-communicable chronic diseases are well established across populations globally. Nevertheless, the prevalence of several lifestyle-related chronic diseases, including cardiovascular disease, varies markedly across countries and ethnicities. Direct ethnic comparative studies on the health benefits of physical activity are sparse and evidencebased physical activity guidelines are not ethnicity-specific. Indeed, physical activity guidelines in some Asian countries were developed primarily based on data from Western populations even though the magnitude of potential benefit may not be the same among different ethnic groups. Unfavorable diurnal perturbations in postprandial triglycerides and glucose are risk factors for cardiovascular disease. This narrative review summarizes differences in these risk factors primarily between individuals of Asian and white European descent but also within different Asian groups. Moreover, the variable effects of physical activity on mitigating risk factors among these ethnic groups are highlighted along with the underlying metabolic and hormonal factors that potentially account for these differences. Future ethnic comparative studies should include investigations in understudied ethnic groups, such as those of East Asian origin, given that the effectiveness of physical activity for ameliorating cardiovascular disease varies even among Asian groups.

\section{Introduction}

Triglycerides (TG) and glucose are the predominant elevated substrates in the circulation in the postprandial period. Evidence from prospective epidemiological studies has shown that postprandial hypertriglyceridemia and hyperglycemia are risk factors for cardiovascular disease and all-cause mortality in men and women [1-4]. Given that most individuals consume several meals throughout the day, the postprandial state represents the usual metabolic state 
and regular postprandial metabolic disturbances may contribute to the progression of atherosclerosis over the lifespan [5, 6].

Postprandial triglyceridemia and glycemia can be defined as the rise in blood TG and glucose concentrations, respectively, observed after consumption of meal(s) or energy- containing beverages. A large and consistent body of evidence shows that an acute bout of aerobic exercise can ameliorate the rises in TC and glucose seen after meals in humans [7-11]. However, most of these studies have been conducted in populations of white European descent. Nevertheless, the available data indicates that physical activity also mitigates postprandial rises in TG and glucose in individuals from different Asian groups [12-15]. However, the threshold level of activity needed to lower TG and glucose may not be the same across all ethnic groups [16]. Although direct ethnic comparisons of postprandial TG and glucose responses to acute exercise are sparse, some studies highlight that the extent of improvement seen with a single bout of exercise is greater in South Asians than white Europeans [17-21]. Evidence also suggests that there are ethnic differences in factors associated with the regulation of postprandial TG and glucose metabolism including insulin sensitivity and pancreatic $\beta$-cell function [22], whole-body fat oxidation during exercise [23], and plasma lipoprotein lipase (LPL) activity $[24,25]$. It is conceivable that these factors, either alone or in combination, could contribute to explaining the variation in the extent of exercise-induced reductions in postprandial TG and glucose between ethnicities.

Examining differences in cardiovascular disease risk factors by ethnicity is important because current physical activity guidelines do not distinguish recommendations based on ethnicity [26-28]. Moreover, the optimal level of physical activity for prevention of cardiovascular disease among different ethnic groups has not been firmly established [29]. This narrative review summarizes differences in postprandial TG, glucose, and insulin metabolism primarily between Asians and white Europeans, but also among Asians compared with other ethnic groups where evidence is available. The variable effect of physical activity on postprandial metabolism is scrutinized among these ethnic groups and potential factors underscoring the ethnic-related differences are considered. The intention of this review is not to provide a systematic or exhaustive account of studies in this area. Rather, we aim to identify and evaluate the most relevant studies that compare the effect of physical activity on postprandial TG, glucose, and insulin with the objective of clarifying the existing knowledge and status of research in this area and identifying future important avenues of investigation.

\section{Postprandial TG Metabolism in Asians}

The prevalence of cardiovascular disease and type 2 diabetes varies considerably across different countries and ethnicities [30,31]. Evidence suggests that individuals of Asian descent, particularly those of South Asian ancestry, are at greater risk of cardiovascular disease and type 2 diabetes compared with individuals of white European descent $[32,33]$. Direct ethnic comparisons of postprandial metabolic responses are sparse, but available studies affirm that there are differences in postprandial TG responses primarily between South Asians and white Europeans ( $>$ Tables 1 and $>\mathbf{2}$ ). To the authors' knowledge, only four previous studies have directly compared postprandial TG responses between South Asians and white Europeans using oral high-fat test meals $[17,18,21,34]$. In three of these studies, elevated TG concentrations were observed in response to highfat meals in young, healthy South Asians (Indian, Pakistani, and/or Sri Lankan descent) in the United Kingdom (UK) $[17,18]$ and in South Asians (Indian, Pakistani, Bangladeshi, or other (not specified) descent) in the UK who were older and overweight [21] compared with individuals of white European descent in the UK of a similar age and body mass index (BMI) range. Conversely, Cruz and colleagues [34] found no ethnic difference in postprandial TG concentrations when a high-fat test meal was provided to eight South Asian (Indian and Sri Lankan descent) and nine Northern European men and women aged 22-40 years residing in the UK who were classified as either normal weight or overweight. A possible explanation for this discrepancy may be the test meals consumed. Although the percentage energy from fat provided in the test meals was similar among the studies (52-57\% energy from fat), the total energy consumed (not stated in the study by Cruz and colleagues) may have differed. In addition, the differences in the main fat sources might partly contribute to this discrepancy among studies. For example, Arjunan and colleagues used dairy as the primary source of fat, which contains a high proportion of short and medium-chain fatty acids that are delivered directly to the liver via the portal vein $[17,18]$. This contrasts with the longer-chain monounsaturated fatty acids found in macadamia nuts used by Cruz and colleagues, which are delivered directly into the circulation via the thoracic duct [34]. Differences in the type of fat used could affect partitioning of fatty acids between chylomicrons and very-low-density lipoproteins as well as the overall postprandial response [7, 35].

Another possible explanation for the discrepancy among studies is that the percentage body fat was similar between the South Asian and white European individuals in the study of Cruz and colleagues (24.2 vs. $24.4 \%$, respectively) [34], whereas it was 1.4-1.7 times higher in the South Asians than white Europeans in the two studies of Arjunan and colleagues (23.0 \pm 4.4 vs. $16.4 \pm 4.2 \%$, mean \pm SD, respectively [17]; and $21.7 \pm 6.0$ vs. $12.5 \pm 4.6 \%$, respectively [18]). In addition, Arjunan and colleagues reported that in one study, the between-group difference in postprandial TG was no longer statistically significant after adjusting for age and body fat percentage [18]. It has been reported that adiposity, in particular visceral adipose tissue accumulation, is associated with impaired postprandial TG-rich lipoprotein clearance [36] and insulin resistance [37]. Compensatory hyperinsulinemia resulting from insulin resistance is thought to decrease skeletal muscle LPL, and this could therefore impair one of the major mechanisms for removal of TG from the circulation [38]. In addition, insulin resistance may exaggerate the postprandial TG response by inhibiting the normal suppressive action of insulin on hepatic very-low-density lipoprotein production [39]. The potential mechanisms via which postprandial hypertriglyceridemia and hyperglycemia are influenced by ethnicity are shown in - Figure 1. Thus, it is possible that the elevated postprandial TG response exhibited by the South Asians in the studies of Arjunan and colleagues $[17,18]$ and Yates and colleagues [21] were linked with a degree of insulin resistance. In support of this notion, the South Asian individuals exhibited greater fasting and postprandial insulin concentrations and/or greater homeostasis model assessment of insulin resistance (HOMA-IR) and insulin resistance index in these studies than their white Euro- 


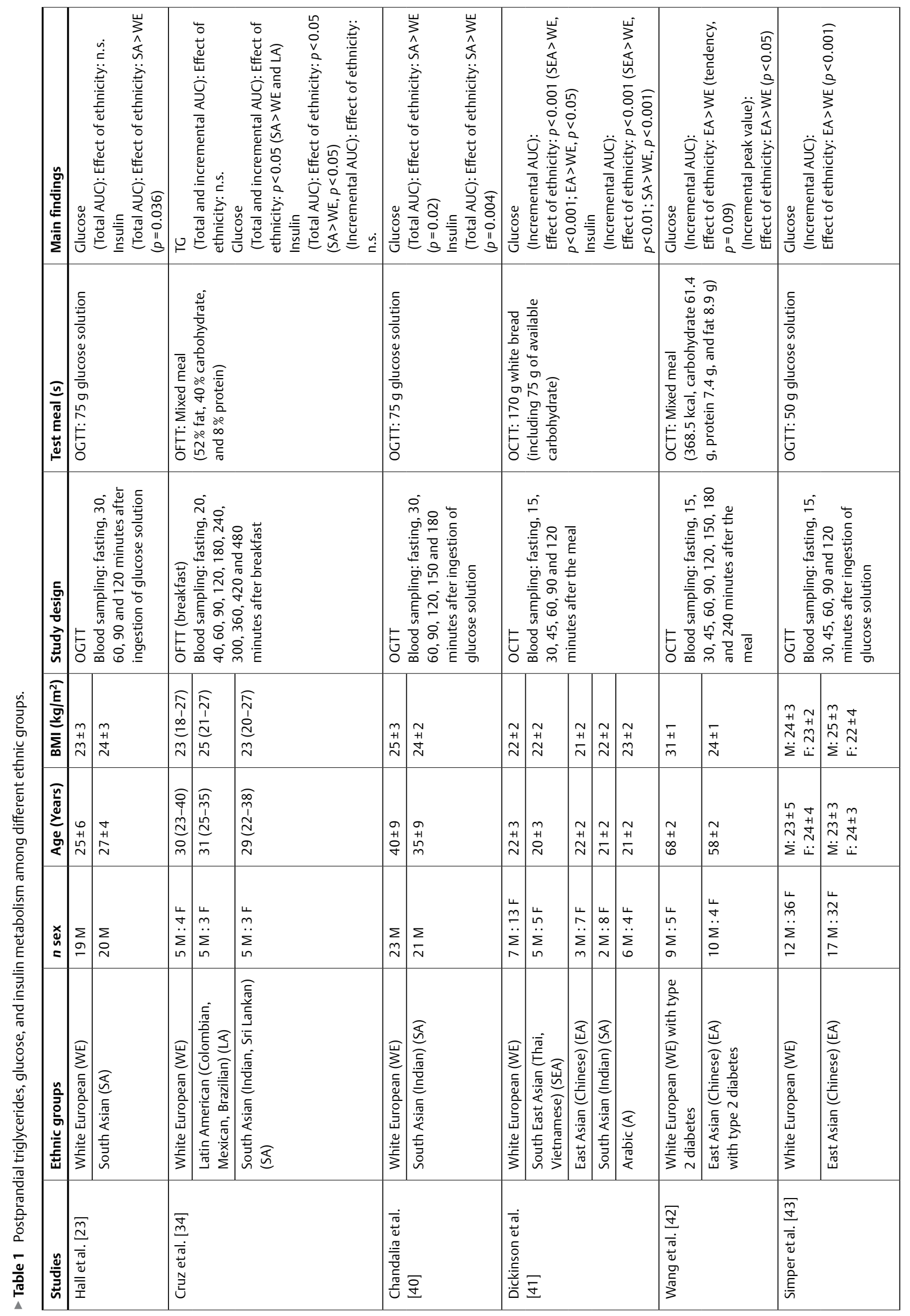




\begin{tabular}{|c|c|c|c|c|c|c|c|c|c|c|c|}
\hline \multicolumn{3}{|c|}{ 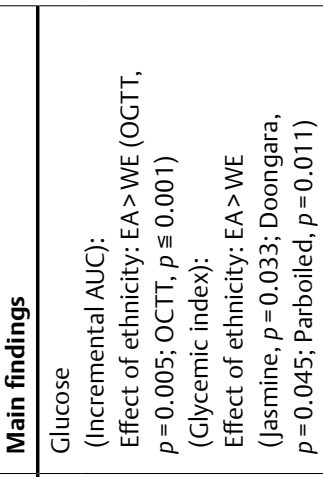 } & \multicolumn{2}{|c|}{ 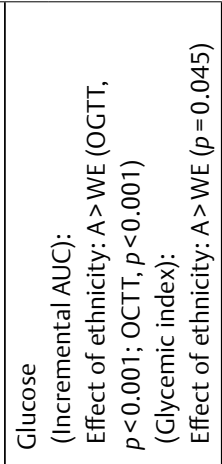 } & \multicolumn{2}{|c|}{ 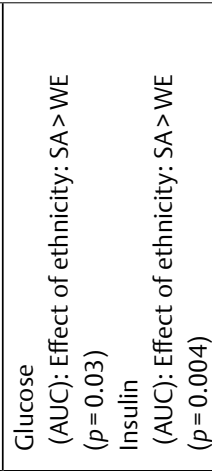 } & \multicolumn{2}{|c|}{ 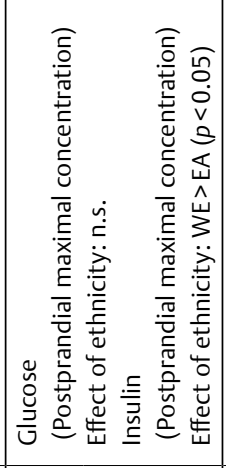 } & \multicolumn{2}{|c|}{ 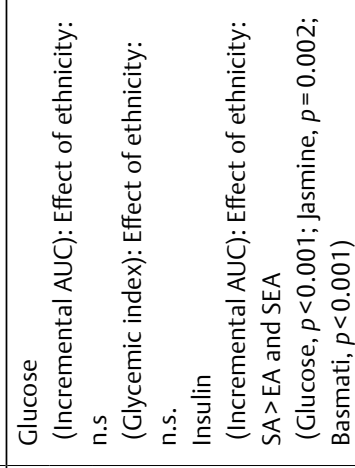 } & 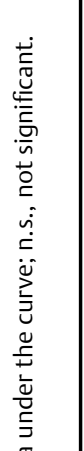 \\
\hline & \multicolumn{2}{|c|}{ 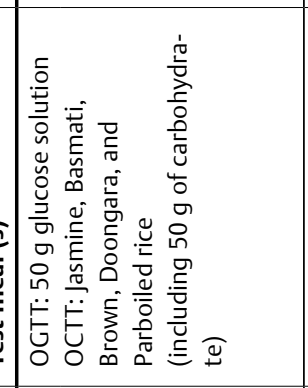 } & \multicolumn{2}{|c|}{ 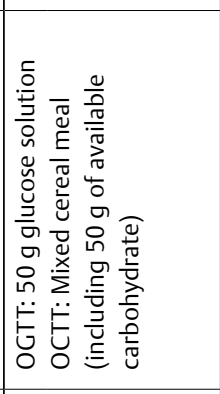 } & \multicolumn{2}{|l|}{ 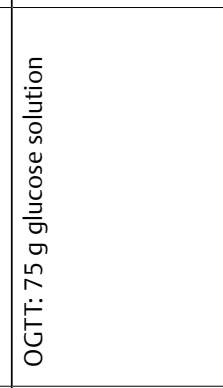 } & \multicolumn{2}{|l|}{ 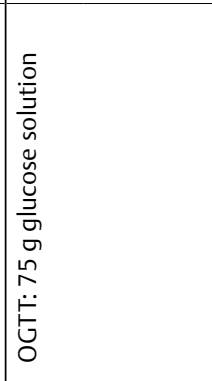 } & \multicolumn{2}{|c|}{ 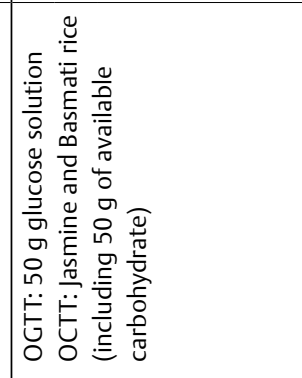 } & 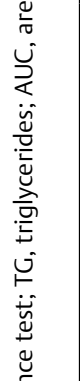 \\
\hline & & 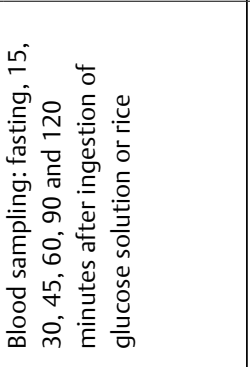 & & 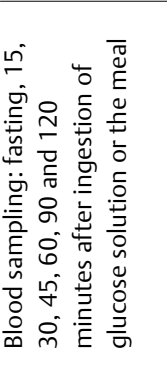 & & 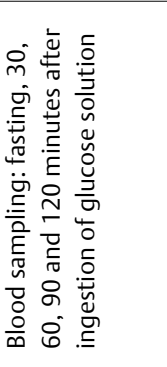 & 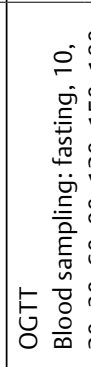 & 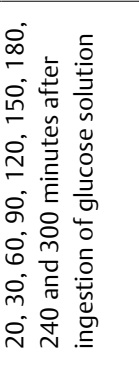 & 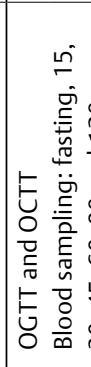 & 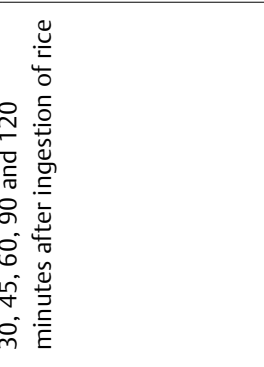 & 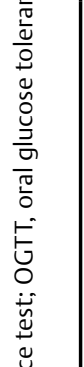 \\
\hline 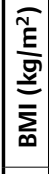 & $\begin{array}{l}\text { in } \\
+1 \\
\stackrel{1}{N} \\
\sim\end{array}$ & $\begin{array}{l}m \\
\stackrel{\sim}{n} \\
\approx\end{array}$ & $\begin{array}{l}+ \\
+1 \\
\sim \\
\sim\end{array}$ & $\begin{array}{l}+ \\
+ \\
N \\
N\end{array}$ & $\mid \begin{array}{c}m \\
+ \\
\stackrel{+}{ \pm} \\
\end{array}$ & $\begin{array}{l}\tilde{N} \\
\stackrel{N}{N} \\
\tilde{N}\end{array}$ & $\begin{array}{l}0 \\
+1 \\
0 \\
m\end{array}$ & $\stackrel{m}{+}$ & \begin{tabular}{l|c}
$\tilde{N}$ & \multirow{1}{+1}{} \\
$\stackrel{N}{N}$ & $\approx$ \\
\end{tabular} & 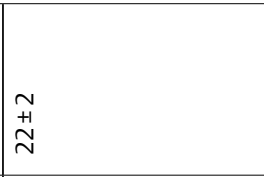 & 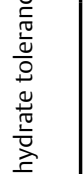 \\
\hline 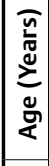 & $\mid \begin{array}{l}\infty \\
+1 \\
+ \\
m\end{array}$ & $\begin{array}{l}\infty \\
+1 \\
m \\
m\end{array}$ & 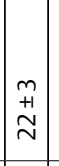 & & $\mid \begin{array}{c}m \\
++1 \\
+1 \\
m \\
m\end{array}$ & $\begin{array}{l}0 \\
++1 \\
+1 \\
\text { m }\end{array}$ & 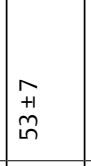 & 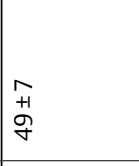 & 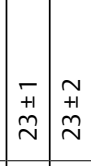 & $\stackrel{+}{\stackrel{+}{N}}$ & 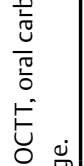 \\
\hline & $\mid \begin{array}{l}u \\
0 \\
0 \\
\check{z} \\
\text { ـn } \\
-\end{array}$ & 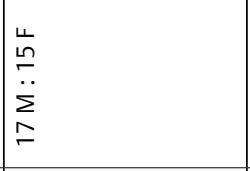 & $\mid$\begin{tabular}{c|} 
\\
$o$ \\
$⿱$ \\
$\ddot{2}$ \\
$m$
\end{tabular} & $\mid \begin{array}{l}u \\
\stackrel{u}{*} \\
\stackrel{\sim}{*} \\
\sigma\end{array}$ & 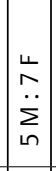 & 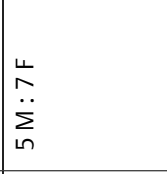 & 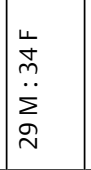 & $\begin{array}{l}\stackrel{L}{\omega} \\
\stackrel{n}{\Sigma} \\
\stackrel{\Sigma}{\Sigma} \\
\bar{N}\end{array}$ & 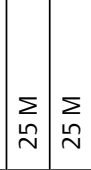 & $\stackrel{\sum}{\stackrel{N}{N}}$ & 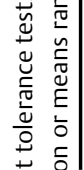 \\
\hline & 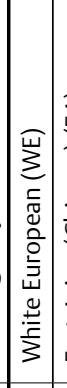 & 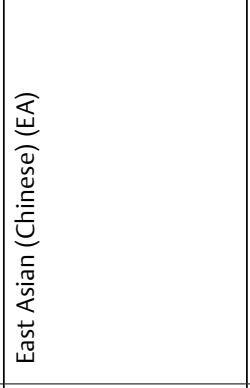 & 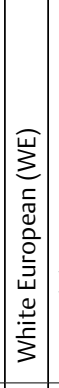 & 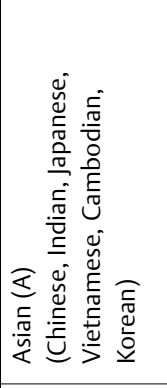 & 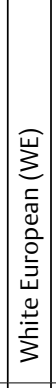 & 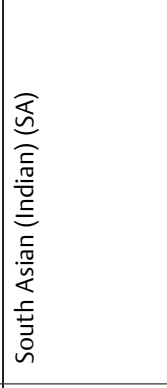 & 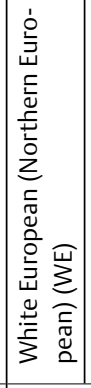 & 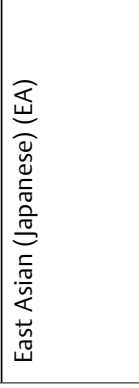 & 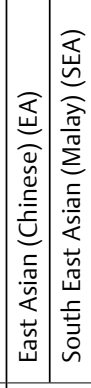 & 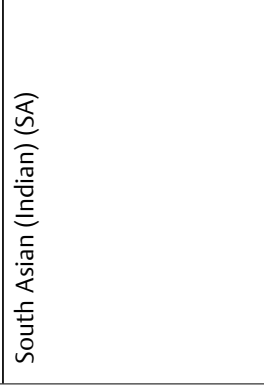 & 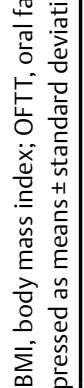 \\
\hline 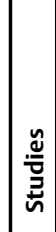 & 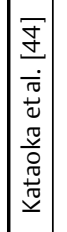 & & 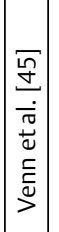 & & 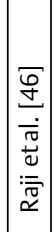 & & 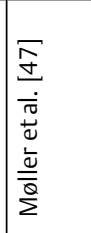 & & 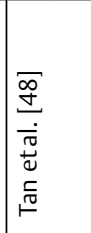 & & 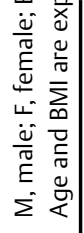 \\
\hline
\end{tabular}




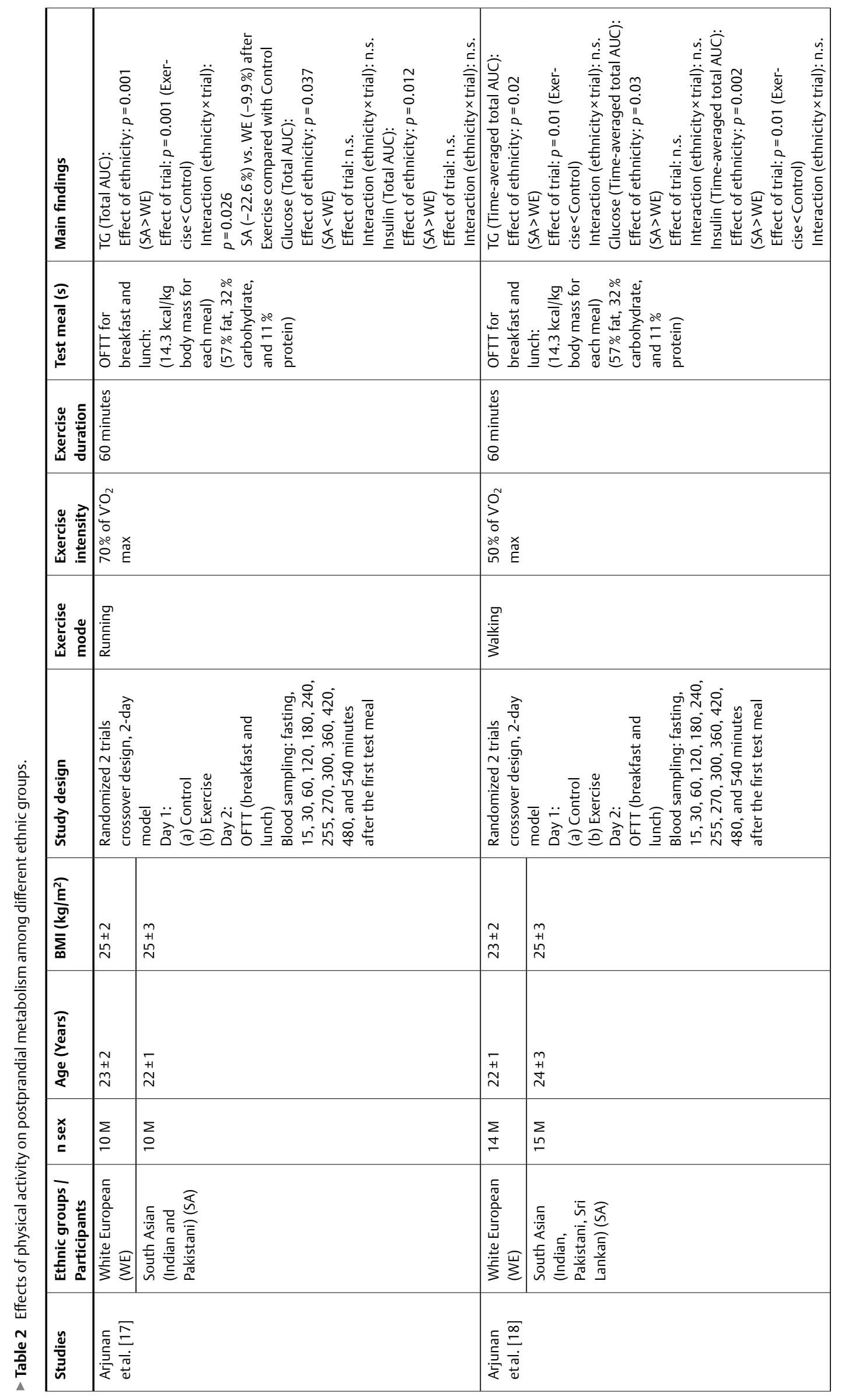




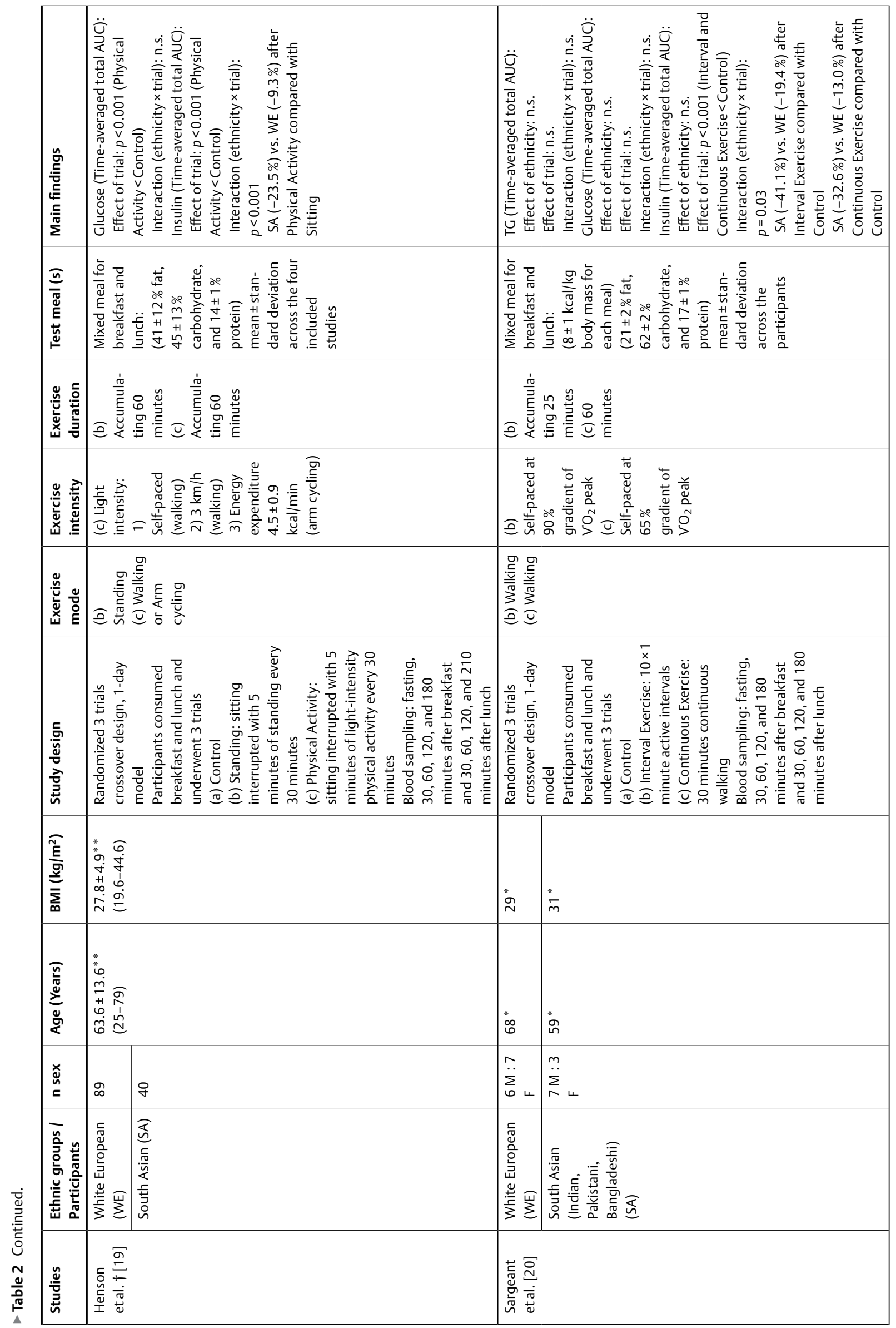




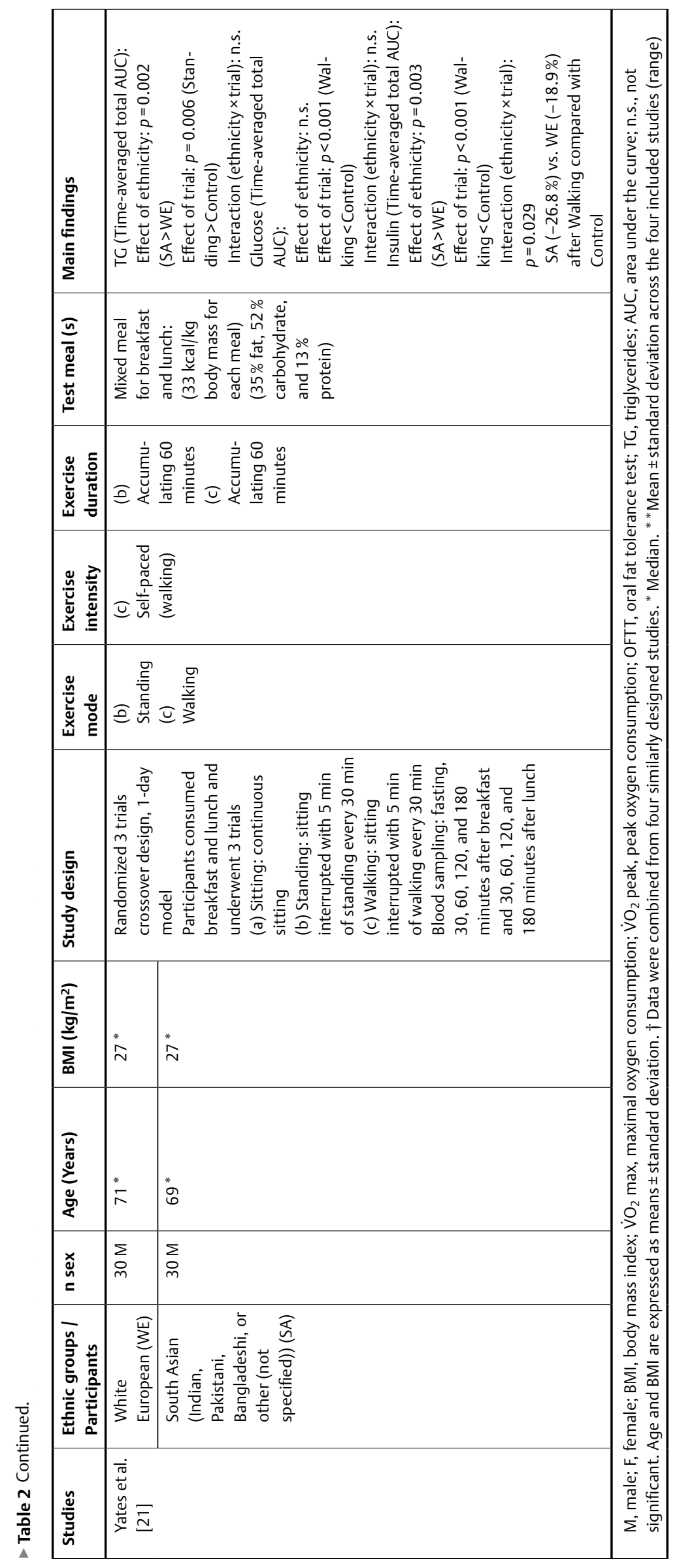




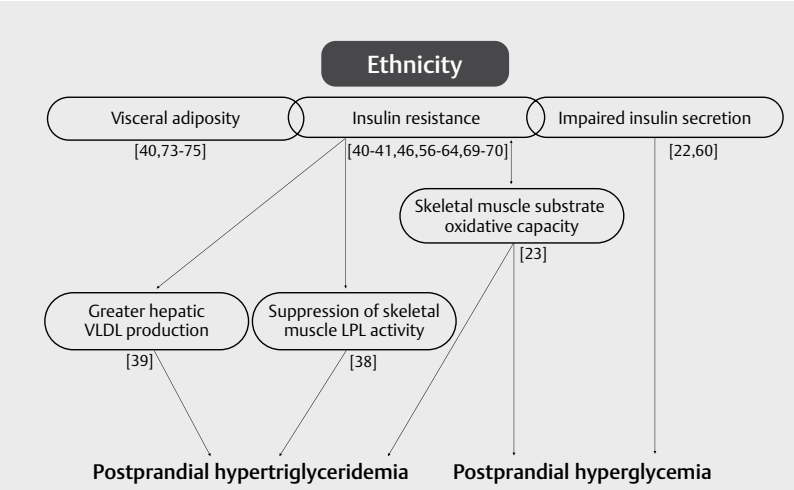

- Figure 1 The potential mechanisms underlying the effects of ethnicity on postprandial hypertriglyceridemia and hyperglycemia. VLDL, very-low-density lipoprotein; LPL, lipoprotein lipase.

pean counterparts $[17,18]$. However, there were no statistical differences in fasting insulin or insulin sensitivity, as assessed by an insulin tolerance test, among the ethnic groups in the study of Cruz and colleagues [34]. Thus, detectable changes in postprandial TG concentrations among ethnicities may only become apparent with concurrent disparities in insulin resistance and/or body fat accumulation.

\section{Postprandial Glucose and Insulin Metabolism in Asians}

Available studies that examine differences in postprandial glucose and insulin responses, using oral glucose or carbohydrate tolerance tests ( $\triangleright$ Table 1 ), typically report greater postprandial glucose [40-46] or insulin responses [23, 40,41,46] in Asians compared with white Europeans. Some studies comparing East Asians (Chinese) with those of white European descent observed that the postprandial glucose incremental area under the curve was greater in ethnic Chinese than people of white European descent despite no statistical difference in fasting blood glucose concentrations [4244]. However, this apparent ethnic difference is not supported universally with another study in East Asians (Japanese) reporting no difference in postprandial maximal glucose concentrations between Japanese individuals living in Japan and white European individuals living in Denmark [47]. A study by Dickinson and colleagues examined differences in postprandial glucose and insulin concentrations among young, healthy men and women from five different ethnic groups (white European, South-East Asian, East Asian, South Asian, and Arabic) in Australia who were matched for age, BMI, waist circumference, and birth weight [41]. The authors found that South-East Asians (Thai and Vietnamese) and East Asians (Chinese) had greater postprandial glucose concentrations than people of white European descent. Moreover, the insulin incremental area under the curve after an oral carbohydrate tolerance test was 2.7 times higher in the South Asians (Indian) and 2.4 times higher in the South East Asians than in people of white European descent. In agreement with this observation, three other studies conducted in the UK or the United States of America (USA) have shown that South Asians (Indian descent) had greater postprandial glucose and insulin responses to an oral glucose tolerance test than people of white European descent of a similar age range, BMI, and fasting glucose concentration $[23,40,46]$.

While consistent evidence shows that Asians exhibit greater postprandial glucose and insulin responses than white Europeans, ethnic differences are apparent in these outcomes even among Asian populations. Tan and colleagues compared postprandial glucose and insulin responses to oral glucose and oral carbohydrate tolerance tests among Chinese, Malay, and Indian men of similar age and BMI in Singapore [48]. Indians had greater postprandial insulin excursions than Chinese and Malays, even after adjustment for percentage body fat or waist circumference whereas there were no differences in postprandial glucose concentrations among the three groups. The authors speculated that the greater insulin response observed in Indians represented a compensatory response to maintain normoglycemia in the presence of greater insulin resistance. The hypothesis that maintenance of normoglycemia was more challenging in Indians was supported by the higher surrogate indicators of insulin resistance (HOMA-IR) and $\beta$-cell function (homeostasis model assessment of $\beta$-cell function (HOMA- $\beta$ )) in this ethnic group compared with Chinese and Malays [48].

The most likely explanations for these ethnic differences in postprandial glucose and insulin - and also TG - are impaired insulin sensitivity and pancreatic $\beta$-cell function mediated mainly by visceral adipose tissue accumulation and also potentially lower skeletal muscle mass (details in "Insulin secretion and sensitivity").

\section{Effects of Physical Activity on Postprandial Metabolism among different Ethnic Groups}

To the authors' knowledge, only five previous studies have directly compared postprandial TG, glucose, and insulin responses to acute exercise bouts between Asians and white Europeans in the UK, in all cases with individuals of South Asian origin [17-21] ( In one study in which Arjunan and colleagues examined running for 60 minutes at $70 \%$ of maximal oxygen uptake $\left(\dot{\mathrm{VO}}_{2}\right.$ max $)$, there was a greater reduction in the postprandial TG response to high-fat meals in South Asians (Indian and Pakistani descent) (-22.6\%) than white Europeans (-9.9\%) despite the South Asians expending less energy during exercise ( $3313 \pm 623$ vs. $3901 \pm 473 \mathrm{~kJ}$, respectively) [17]. However, there were no ethnicity-trial interactions for postprandial glucose and insulin responses. Interestingly, the same group of researchers found no difference in the magnitude of reduction in postprandial TG concentrations between South Asians (Indian, Pakistani, and Sri Lankan descent) and white Europeans after 60 minutes of brisk walking at $50 \%$ of $\dot{\mathrm{VO}}_{2} \max (-8.0$ vs. $-9.9 \%$, respectively) [18]. Furthermore, both groups experienced comparable exercise-induced reductions in postprandial insulin concentrations and postprandial glucose responses were similar irrespective of trial or ethnicity [18]. The reason for the contrasting findings between studies was unclear, but the authors hypothesized that South Asians may require a higher intensity of exercise and/or exercise-induced energy expenditure in order to maximize the reductions in postprandial TG seen acutely with exercise.

Yates and colleagues showed that the magnitude of reduction in postprandial insulin in response to breaking up prolonged sitting with 5-minute bouts of self-paced light-intensity walking every 
30 minutes (accumulating 60 minutes in total) was greater in South Asians (Indian, Pakistani, Bangladeshi, or other (not specified) descent) than white Europeans living in the UK after adjusting for fasting insulin concentrations or insulin resistance ( -26.8 vs. $-18.9 \%$, respectively) [21]. In line with this finding, Henson and colleagues combined the data from four similarly designed randomized acute cross-over studies [21,49-51], all of which included South Asians and white Europeans in the UK. They found that breaking up prolonged sitting with short bouts of light-intensity walking or upperbody exercise (arm ergometry) (5 minutes every 30 minutes) was more effective for reducing postprandial insulin in South Asians than white Europeans (-23.5 vs. $-9.3 \%$, respectively) [19]. Recently, Sargeant and colleagues also reported that the magnitude of reduction in postprandial insulin concentrations in response to interval and continuous exercise was greater in South Asians (Indian, Pakistani, and Bangladeshi descent) than white Europeans in the UK (interval exercise -41.1 vs. $-19.4 \%$, respectively; continuous exercise -32.6 vs. $-13.0 \%$, respectively) [20]. In contrast, no ethnicity-trial interactions for postprandial TG or glucose concentrations were apparent in these three studies [19-21].

The potential for exercise to augment postprandial metabolic health to a greater extent in South Asians may have been due to the elevated TG and insulin total area under the curve, which in the resting (control) trials were 1.7 times and 1.3-2.8 times higher, respectively, in the South Asians [17-21]. Arjunan and colleagues argued that higher control concentrations provide a greater potential for reductions to occur. However, it is important to note that the TC and insulin total area under the curve in the exercise trials in the South Asians were still 1.3 times and 1.1-2.3 times higher, respectively, than the control trial values in the white Europeans. These results are consistent with a cross-sectional study conducted by Celis-Morales and colleagues who observed that South Asians (Indian, Pakistani, Bangladeshi, and Sri Lankan descent) in the UK may need to undertake greater levels of habitual physical activity than white Europeans in the UK to confer a similar cardiometabolic risk profile, but that the benefits for a given increase in physical activity may be greater in South Asians [16]. The reasons for the ethnic differences in postprandial metabolic responses to acute exercise are not fully understood, but differences in LPL activity $[24,25]$ and substrate oxidation during exercise may be potential explanations [23] (details in "Lipoprotein lipase activity" and "Substrate oxidation during exercise”).

\section{Insulin Sensitivity and Secretion}

Insulin sensitivity and secretion are key regulators of postprandial TG and glucose responses [52-54]. Evidence supports differences in insulin sensitivity and pancreatic $\beta$-cell function between Asians and white Europeans even with normal glucose tolerance. For example, Indian infants who were born in India have been shown to have higher insulin concentrations (and higher subcutaneous fat and leptin) than white European infants born in the UK despite having a lower body weight [55]. Studies have also shown that adolescent South Asians [56], young adult South, East, and South-East Asians [41], and middle-aged adult South and East Asians [57-62] are more insulinresistant based on HOMA-IR and the insulin sensitivity index than those of white European descent of a similar age range. Several in- vestigations using the hyperinsulinemic-euglycemic clamp to measure insulin sensitivity in vivo provide further support for the notion that South, East, and South-East Asians appear more insulin-resistant than people of white European descent across the lifespan from adolescence to mid-adulthood [40,41, 46, 56, 63, 64].

For insulin secretion, Asians have been found to have inherent pancreatic $\beta$-cell dysfunction. For example, Fukushima and colleagues reported that Japanese individuals had lower early- and latephase insulin responses at all stages of glucose intolerance [65]. Indeed, the ability of the $\beta$-cells to respond to even small increases in insulin resistance may be impaired in Asians. In Japanese men with normal glucose tolerance, a lower insulin sensitivity index (a surrogate measure of whole-body insulin sensitivity [66]) was observed alongside a lower insulinogenic index (a surrogate indicator of first-phase insulin secretion to a glucose load) in those with a higher BMI (>27.5 $\mathrm{kg} \cdot \mathrm{m}^{-2}$ ) [67]. The authors speculated that the $\beta$-cells may not compensate sufficiently for insulin resistance in these individuals, which could contribute to the development of glucose intolerance and type 2 diabetes [67]. Supporting these observations, one systematic review and meta-analysis reported that $\beta$-cell dysfunction based on the acute insulin response to glucose was least favorable in East Asians followed in order by white Europeans and those of African descent [22]. Evidence has also shown that East Asians (Japanese and Chinese descent) in the USA have impaired $\beta$-cell function based on HOMA- $\beta$ compared with those of white European descent in the USA [60]. Impaired pancreatic $\beta$-cell function in Asians may be more readily promoted by aging or $\beta$-cell exhaustion due to continuous insulin resistance in the course of exposure to features of modern lifestyles such as high calorie diets and physical inactivity [68].

Although Asians have impaired insulin sensitivity and $\beta$-cell function compared with white Europeans, it is important to recognize that Asians are not a homogeneous group even though the term is often used to encompass a wide range of ethnic backgrounds across a single region that is genetically diverse and has substantial differences in the extent of environmental exposures. Among Asian groups, South Asians are consistently found to be the most insulin-resistant whereas East Asians are the most insulinsensitive $[58,61,62,69,70]$. Furthermore, South Asians (Indian descent) have better $\beta$-cell function than East (Chinese descent) and South-East (Malay descent) Asians [70]. Initially, impaired insulin sensitivity may be compensated by an increased $\beta$-cell response [71]. Thus, the higher $\beta$-cell response in South Asians may indicate impaired insulin sensitivity compared with other ethnic groups. This is important as progression to type 2 diabetes is thought to occur when $\beta$-cells fail to compensate sufficiently for the reduction in insulin sensitivity. In contrast, the pathophysiological progression to type 2 diabetes in East Asians may differ from that of South Asians and is characterized primarily by $\beta$-cell dysfunction [72].

Body fat distribution is likely to play an important role in the pathogenesis of insulin resistance. Studies report that surrogate (i. e., waist circumference, truncal skinfold thickness) and direct (i. e., dual-energy $X$-ray absorptiometry) measures of adiposity are inversely associated with insulin sensitivity $[34,40,56]$. Of these adiposity measurements, visceral adipose tissue accumulation is strongly associated with lower insulin sensitivity. South and East Asians generally have greater visceral adipose tissue and liver fat 
accumulation than those of white European descent at any given age, sex, and BMI [40, 73-75]. However, several studies also report that ethnic differences in insulin sensitivity exist even after adjustment for indices of adiposity (BMI, total body fat, truncal skinfold thickness, and visceral abdominal fat area) as potential confounders $[40,57]$. These results imply that other biological factors (i. e., adiponectin concentrations, secretion of incretin hormones) $[59,61,76]$ and lifestyle behaviors (i. e., dietary habits, physical activity levels) may also contribute to ethnic differences in insulin sensitivity.

\section{Lipoprotein Lipase Activity}

Lipoprotein lipase is a key enzyme in the removal of TG from the blood stream. This enzyme is bound at the capillary endothelium of several tissues, such as adipose tissue and skeletal muscle $[77,78]$. The main function of LPL is to catalyze the hydrolysis of TG packaged in the core of circulating TG-rich lipoproteins, including chylomicrons and very-low-density lipoproteins. The fatty acids liberated by the action of LPL are taken into adipose tissue and skeletal muscle for storage or oxidation as an energy substrate. There is strong evidence that post-heparin plasma LPL correlates positively with fasting TG concentrations [24, 79] and the clearance of postprandial TG [80]. The activity of adipose tissue LPL is mainly upregulated in response to insulin secretion after consumption of a meal whereas LPL activity of skeletal muscle is mainly upregulated in response to exercise [81,82]. Studies directly comparing LPL mass and/or activity between different ethnic groups are limited to comparisons between individuals of white European and African descent [24, 25, 79, 83, 84]. We are unaware of any studies that have directly compared LPL mass and/or activity between Asians and other ethnic groups. Friday and colleagues and Bower and colleagues examined postprandial TG responses in relation to LPL mRNA and protein mass in adipose tissue and post-heparin plasma LPL activity in white European and African descent men [24] and women [25] in the USA. These studies found that the clearance rate of TG from the circulation after a high-fat meal was higher in individuals of African descent than white European descent. This greater TG clearance in those of African descent was accompanied by a greater LPL protein mass in subcutaneous adipose tissue and higher post-heparin plasma LPL activity compared with those of white European descent. These results suggest the pathway for TG clearance from the circulation after meal intake appears more efficient in individuals of African descent than white European descent, most likely due to an elevated LPL mass and activity.

Although no studies have compared LPL mass and activity directly between Asians and those of white European descent, some studies have investigated ethnic variation in the frequency of LPL gene mutations and polymorphisms related to TG concentrations in the circulation [85-88]. The -93G/T mutation on the LPL gene has previously been reported as having a favorable TG-lowering effect by increasing LPL gene expression [87]. It has been shown that there are marked differences in the frequency of the -93G/T mutation between white Europeans, Africans, and Asians [86, 87]. The frequency of the $-93 \mathrm{G}$ allele was lowest in East Asians (0\%), was rare in both South Asians (2.9-4.4\%) and white Europeans (2.2-3.4\%), but was the predominant mutation in individuals of African descent
(40.7-76.4\%) [86-88]. In accordance with -93G/T mutation, the frequency of D9N mutation, asparagine for aspartic acid change at residue 9 on the $L P L$ gene (D9N) in relation to the TG-raising effect [89] has been shown to be positively associated with -93G/T mutation $[85,88]$. Again, this mutation was lowest in Asians ( $0 \%$ in Chinese and Indians), intermediate in the white Europeans (1.7$2.8 \%$ ) and greatest in those of African descent (11.0-12.4\%). Whether these ethnic variations in the frequency of LPL gene mutations contribute to the ethnic differences in postprandial TG concentrations has not been established. However, the effect of LPL gene mutations on the magnitude of TG concentrations has been confirmed in studies of single ethnicity or mixed ethnicity involving Black South Africans, African Americans, Hispanics, and white Europeans. Specifically, individuals with the -93G/9D haplotype (-93G is the rare type allele for -93G/T mutation, 9D is the wild type allele for D9N) (i.e., TG/DD or GG/DD) exhibited 19-28\% lower fasting TC concentrations [85, 86] and/or 31-32\% lower postprandial TG concentrations $[85,87]$ than those with the -93T/9D haplotype (i. e., TT/DD). This TG-lowering effect associated with the -93G allele is thought to be due to greater promoter activity of the LPL gene [87].

In contrast to these findings, Hall and colleagues found no ethnic variation in the frequencies of five common LPL gene mutations related to circulating TG levels (-93T/G, D9N, N291S, S447X, and the Hind III) [85-87, 90-92] in individuals of South Asian, white European, and African descent [88]. However, no meaningful association of these mutations was observed with fasting TG concentrations. Collectively, ethnic variation in LPL mass and/or activity may contribute to the ethnic differences in the magnitude of the postprandial TG response between Asians and white Europeans, but experimental work is required to confirm this assertion. This should include studies comparing the association between LPL and postprandial TG metabolism among Asians and other ethnic groups to develop a better understanding of the potential mechanism(s) underscoring ethnic variation in postprandial TG metabolism.

\section{Substrate Oxidation during Exercise}

As stated earlier, insulin sensitivity is a key factor that influences postprandial TG and glucose metabolism with several studies demonstrating that adiposity, particularly visceral adipose tissue accumulation, strongly contributes to impaired insulin sensitivity $[34,40,56,58]$. However, adiposity per se may not be the only determinant for impaired insulin sensitivity as differences among groups remain even after adjusting for indices of adiposity as confounding measurements $[40,57]$. It is possible that differences in skeletal muscle substrate oxidation may play a role. Maximal oxygen uptake, an index of oxidative capacity at the whole-body level, is closely associated with skeletal muscle lipid oxidative capacity [23]. Cardiorespiratory fitness and skeletal muscle oxidative capacity contribute to insulin sensitivity $[93,94]$ partly due to intramyocellular lipids, such as diacylglycerol and ceramide, activating signaling pathways that may induce insulin resistance in skeletal muscle [95]. Hall and colleagues found that healthy young South Asian men in the UK had $19-23 \%$ lower $\dot{\mathrm{VO}}_{2}$ max and $~ 40 \%$ lower fat oxidation rates during a sub-maximal exercise test than white European men of a similar age and BMI range in the UK. They also showed that the same men had a lower insulin sensitivity index and lower 
skeletal muscle Ser473 phosphorylation of protein kinase B, a key insulin signaling protein, than white European men even after adjusting for age, $\mathrm{BMI}$, and fat mass. In addition, $\dot{\mathrm{V}}_{2}$ max and fat oxidation rates during a sub-maximal exercise test were positively correlated with the insulin sensitivity index, and with skeletal muscle protein kinase B Ser473 phosphorylation even after adjusting for age, BMI, fat mass, and physical activity. The regression slopes of these relationships did not differ between South Asians and white Europeans. Therefore, the difference in insulin sensitivity among the groups was no longer apparent after adjusting for $\dot{\mathrm{VO}}_{2}$ max or for fat oxidation rates [23].

In contrast to whole-body oxidation, Hall and colleagues showed that South Asians in the UK exhibited greater expression of skeletal muscle genes involved in oxidative and lipid metabolism than white Europeans in the UK [23]. In addition, expected positive correlations were seen between skeletal muscle gene expression and fat oxidation rates during exercise in white Europeans; however, negative correlations were observed in South Asians. These findings are consistent with those of Nair and colleagues who reported that South Asian (Indian descent) men in the USA, irrespective of their diabetic status, had greater skeletal muscle expression of genes involved in oxidative phosphorylation and the citrate cycle than those of white European descent of similar age and BMI range in the USA [96]. Moreover, the capacity for mitochondrial adenosine triphosphate production was higher in South Asians than those of white European descent, although South Asians were substantially more insulin-resistant [96]. Collectively, these data indicate that reduced oxidative capacity and fatty acid utilization at the whole-body level are key features of the impaired insulin sensitivity observed in South Asians irrespective of mitochondrial function and skeletal muscle gene expression of oxidative and lipid metabolism. Impaired fat oxidation during exercise in South Asians likely represents a defect in substrate delivery to muscle. South Asian (India, Bangladesh, Sri Lanka, or Pakistan descent) men living in the UK have impaired endothelial function [97] and reduced nitric oxide bioavailability both at rest and during exercise [98]. This might reflect a compensatory adaptation within muscle in response to impaired microvascular perfusion leading to reduced fuel delivery.

A previous systematic review identified several genetic variants associated with cardiorespiratory trainability after aerobic exercise training interventions (e. g., genes associated with muscular subsystems, electrolyte balance, lipid metabolism, oxidative phosphorylation and energy production, and oxygen delivery) [99]. While these findings appear exciting, it is uncertain whether these genetic variants contribute to differences in the metabolic benefits of physical activity - specifically postprandial metabolism in this instance - among ethnic groups. Previous studies examining the role of genetic variants as potential predictors of the exercise training response have focused primarily on white European populations (74.5\% white European) [99]. Further exploration across ethnicities is required to identify genetic variants that can potentially affect fitness adaptations to exercise training.

\section{Future Directions}

Given that direct ethnic comparisons of the health benefits of physical activity are sparse, and that evidence-based physical activity guidelines are not ethnicity-specific [26-28], more research in all Asian populations, including those that have been studied more frequently, is needed to expand the evidence base. It is also important to recognize that Asians are not a homogeneous group and the metabolic health responses to physical activity in South Asian individuals addressed in this review may not be representative of other Asian groups because the effectiveness of physical activity on some risk markers for cardiovascular disease may vary. Future ethnic comparative studies should include investigations in understudied ethnic groups such as those of East Asian origin [100]. The importance of diversifying ethnic-based research to East Asian populations is underscored by the upward trajectory in adverse coronary heart disease risk factors including dyslipidemia, diabetes, and obesity apparent in these populations in recent years [101, 102]. This rationale is strengthened further by evidence demonstrating that levels of physical inactivity are high in high-income East Asian countries as well as in European countries [103].

There is also a distinct lack of research in women, particularly in examining the efficacy of exercise to augment postprandial metabolic health, highlighting the need for research efforts to extend ethnic-focused investigations to both sexes. Future studies are also required to disentangle the independent effects of ethnicity and adiposity/insulin resistance on the various postprandial outcomes both with and without an exercise stimulus. Further investigations into LPL mass and/or activity and substrate oxidation in Asian groups may help to elucidate potential mechanism(s) responsible for ethnic differences in postprandial metabolism. Finally, the extant exercise-based literature has primarily been restricted to studies implementing single bouts of exercise; therefore, studying ethnic differences in postprandial metabolic responses to chronic exercise protocols is required before the longer-term implications for chronic disease risk can be established.

\section{Conclusion}

This narrative review summarizes the effects of physical activity on postprandial TG, glucose, and insulin metabolism between Asians and white Europeans and highlights some of the known differences within Asian groups. Available studies demonstrate greater postprandial TG, glucose, and insulin responses to meals in Asians than white Europeans, with some evidence that South Asians may exhibit greater exercise-induced reductions in postprandial insulin, and possibly TG, than white Europeans. The most likely explanation for these ethnic differences is impaired insulin sensitivity mediated by visceral adipose tissue accumulation and impaired pancreatic $\beta$-cell function more readily promoted by modern lifestyles including high calorie diets and physical inactivity in Asians. In addition, differences in LPL mass and/or activity or substrate oxidation may contribute to ethnic differences in postprandial TG metabolism; however, further research is required before firm conclusions can be drawn. An improved understanding of the postprandial metabolic health benefits of physical activity across ethnic groups may help to optimize lifestyle-based approaches that diminish the future risk of chronic diseases in those ethnicities with an underlying predisposition. 


\section{Acknowledgements}

$\mathrm{CN}$ wrote the first version of the manuscript. All authors contributed to the conceptual idea and critically reviewed and edited the manuscript. AET and DJS acknowledge support from the National Institute for Health Research (NIHR) Leicester Biomedical Research Centre. The views expressed are those of the authors and not necessarily those of the NHS, the NIHR or the Department of Health. This study forms part of the initial work towards the PhD thesis of $\mathrm{CN}$.

\section{Conflict of Interest}

All authors declare that there is no conflict of interest. The manuscript meets the ethical standards of the IJSM [104].

\section{References}

[1] Tominaga M, Eguchi $\mathrm{H}$, Manaka $\mathrm{H}$ et al. Impaired glucose tolerance is a risk factor for cardiovascular disease, but not impaired fasting glucose. The Funagata Diabetes Study. Diabetes Care 1999; 22: 920-924

[2] The DECODE Study Group. Glucose tolerance and mortality: comparison of WHO and American Diabetes Association diagnostic criteria. Lancet 1999; 354: 617-621

[3] Iso $\mathrm{H}$, Naito $\mathrm{Y}$, Sato $\mathrm{S}$ et al. Serum triglycerides and risk of coronary heart disease among Japanese men and women. Am J Epidemiol 2001; 153: 490-499

[4] Nordestgaard BG, Benn M, Schnohr P et al. Nonfasting triglycerides and risk of myocardial infarction, ischemic heart disease, and death in men and women. JAMA 2007; 298: 299-308

[5] Zilversmit DB. Atherogenesis : A postprandial phenomenon. Circulation 1979; 60: 473-485

[6] Marcovecchio ML, Lucantoni M, Chiarelli F. Role of chronic and acute hyperglycemia in the development of diabetes complications. Diabetes Technol Ther 2011; 13: 389-394

[7] Peddie MC, Rehrer NJ, Perry TL. Physical activity and postprandial lipidemia: are energy expenditure and lipoprotein lipase activity the real modulators of the positive effect? Prog Lipid Res 2012; 51: $11-22$

[8] Maraki M, Sidossis L. The latest on the effect of prior exercise on postprandial lipaemia. Sports Med 2013; 43: 463-481

[9] Freese EC, Gist NH, Cureton K]. Effect of prior exercise on postprandial lipemia: an updated quantitative review. J Appl Physiol (1985) 2014; 116: 67-75

[10] Haxhi ], Scotto A, Sacchetti M. Exercising for metabolic control: is timing important? Ann Nutr Metab 2013; 62: 14-25

[11] Aqeel M, Forster A, Richards EA et al. Correction: The effect of timing of exercise and eating on postprandial response in adults: a systematic review. Nutrients 2020; 12: 221

[12] Lye CT, Mukherjee S, Burns SF. Combining plant sterols with walking lowers postprandial triacylglycerol more than walking only in Chinese men with elevated body mass index. Int I Sport Nutr Exerc Metab 2019; 29: 576-582

[13] Miyashita M, Hamada Y, Fujihira K et al. Energy replacement diminishes the postprandial triglyceride-lowering effect from accumulated walking in older women. Eur J Nutr 2020; 59: 2261-2270

[14] Miyashita M, Edamoto K, Kidokoro T et al. Interrupting sitting time with regular walks attenuates postprandial triglycerides. Int J Sports Med 2016; 37: 97-103
[15] Hatamoto Y, Goya R, Yamada Y et al. Effect of exercise timing on elevated postprandial glucose levels. J Appl Physiol (1985) 2017; 123 : 278-284

[16] Celis-Morales CA, Ghouri N, Bailey MES et al. Should physical activity recommendations be ethnicity-specific? Evidence from a cross-sectional study of South Asian and European men. PLoS One 2013; 8: e82568

[17] Arjunan SP, Bishop NC, Reischak-Oliveira A et al. Exercise and coronary heart disease risk markers in south Asian and European men. Med Sci Sports Exerc 2013; 45: 1261-1268

[18] Arjunan SP, Deighton K, Bishop NC et al. The effect of prior walking on coronary heart disease risk markers in South Asian and European men. Eur J Appl Physiol 2015; 115: 2641-2651

[19] Henson J, Edwardson CL, Celis-Morales CA et al. Predictors of the acute postprandial response to breaking up prolonged sitting. Med Sci Sports Exerc 2020; 52: 1385-1393

[20] Sargeant J, Jelleyman C, Coull NA et al. Improvements in glycaemic control after acute moderate-intensity continuous or high-intensity interval exercise are greater in South Asians than white Europeans with nondiabetic hyperglycaemia : A randomised crossover study. Diabetes Care 2021; 44: 201-209

[21] Yates T, Edwardson CL, Celis-Morales C et al. Metabolic effects of breaking prolonged sitting with standing or light walking in older south asians and white Europeans: a randomized acute study. J Gerontol A Biol Sci Med Sci 2020; 75: 139-146

[22] Kodama K, Tojjar D, Yamada S et al. Ethnic differences in the relationship between insulin sensitivity and insulin response: a systematic review and meta-analysis. Diabetes Care 2013; 36: 1789-1796

[23] Hall LML, Moran CN, Milne GR et al. Fat oxidation, fitness and skeletal muscle expression of oxidative/lipid metabolism genes in South Asians: implications for insulin resistance? PLoS One 2010; 5: e14197

[24] Friday KE, Srinivasan SR, Elkasabany A et al. Black-white differences in postprandial triglyceride response and postheparin lipoprotein lipase and hepatic triglyceride lipase among young men. Metabolism 1999; 48: 749-754

[25] Bower JF, Deshaies Y, Pfeifer M et al. Ethnic differences in postprandial triglyceride response to a fatty meal and lipoprotein lipase in lean and obese African American and Caucasian women. Metabolism 2002; 51: 211-217

[26] World Health Organization, WHO Guidelines on Physical Activity and Sedentary Behaviour. 2020; Available from: https://apps.who.int/iris/ bitstream/handle/10665/44399/9789241599979_eng. pdf? sequence $=1$. Accessed: 12 May 2021

[27] Department of Health and Social Care. UK Chief Medical Officers' Physical Activity Guidelines. 2019; Available from: https://assets. publishing.service.gov.uk/government/uploads/system/uploads/ attachment_data/file/832868/uk-chief-medical-officers-physicalactivity-guidelines.pdf. Accessed: 25 March 2021

[28] Physical Activity Guidelines Advisory Committee. U.S. Department of Health and Human Services. Physical Activity Guidelines for Americans (2nd edition). 2018; Available from: https://health.gov/ sites/default/files/2019-09/Physical_Activity_Guidelines_2nd_edition.pdf. Accessed: 25 March 2021

[29] Gill JMR, Celis-Morales CA, Ghouri N. Physical activity, ethnicity and cardio-metabolic health: does one size fit all? Atherosclerosis 2014; 232: 319-333

[30] International Diabetes Federation. IDF Diabetes Atlas. $9^{\text {th }}$ ed. Brussels: International Diabetes Federation; 2019

[31] Roth GA, Johnson C, Abajobir A et al. Global, regional, and national burden of cardiovascular diseases for 10 causes, 1990-2015. J Am Coll Cardiol 2017; 70: 1-25 
[32] Gholap N, Davies M, Patel K et al. Type 2 diabetes and cardiovascular disease in South Asians. Prim Care Diabetes 2011; 5: 45-56

[33] Sattar N, Gill JMR. Type 2 diabetes in migrant south Asians: mechanisms, mitigation, and management. Lancet Diabetes Endocrinol 2015; 3: 1004-1016

[34] Cruz ML, Evans K, Frayn KN. Postprandial lipid metabolism and insulin sensitivity in young Northern Europeans, South Asians and Latin Americans in the UK. Atherosclerosis 2001; 159: 441-449

[35] Lopez-Miranda J, Williams C, Larion D. Dietary, physiological, genetic and pathological influences on postprandial lipid metabolism. $\mathrm{Br}$ J Nutr 2007; 98: 458-473

[36] Couillard C, Bergeron N, Prud'Homme D et al. Postprandial triglyceride response in visceral obesity in men. Diabetes 1998; 47 : 953-960

[37] Hocking S, Samocha-Bonet D, Milner KL et al. Adiposity and insulin resistance in humans: the role of the different tissue and cellular lipid depots. Endocr Rev 2013; 34: 463-500

[38] Pollare T, Vessby B, Lithell H. Lipoprotein lipase activity in skeletal muscle is related to insulin sensitivity. Arterioscler Thromb 1991; 11 : 1192-1203

[39] Malmström R, Packard C], Caslake M et al. Defective regulation of triglyceride metabolism by insulin in the liver in NIDDM. Diabetologia 1997; 40: 454-462

[40] Chandalia M, Abate N, Garg A et al. Relationship between generalized and upper body obesity to insulin resistance in Asian Indian men. J Clin Endocrinol Metab 1999; 84: 2329-2335

[41] Dickinson S, Colagiuri S, Faramus E et al. Postprandial hyperglycemia and insulin sensitivity differ among lean young adults of different ethnicities. J Nutr 2002; 132: 2574-2579

[42] Wang X, Xie C, Marathe CS et al. Disparities in gastric emptying and postprandial glycaemia between Han Chinese and Caucasians with type 2 diabetes. Diabetes Res Clin Pract 2020; 159: 107951

[43] Simper T, Dalton C, Broom D et al. Greater glycaemic response to an oral glucose load in healthy, lean, active and young chinese adults compared to matched Caucasians. Nutrients 2018; 10: 487

[44] Kataoka M, Venn BJ, Williams SM et al. Glycaemic responses to glucose and rice in people of Chinese and European ethnicity. Diabet Med 2013; 30: e101-107

[45] Venn BJ, Williams SM, Mann JI. Comparison of postprandial glycaemia in Asians and Caucasians. Diabet Med 2010; 27: 1205-1208

[46] Raji A, Seely EW, Arky RA et al. Body fat distribution and insulin resistance in healthy Asian Indians and Caucasians. J Clin Endocrinol Metab 2001; 86: 5366-5371

[47] Møller JB, Man CD, Overgaard RV et al. Ethnic differences in insulin sensitivity, $\beta$-cell function, and hepatic extraction between Japanese and Caucasians: a minimal model analysis. J Clin Endocrinol Metab 2014; 99: 4273-4280

[48] Tan VMH, Wu T, Henry C] et al. Glycaemic and insulin responses, glycaemic index and insulinaemic index values of rice between three Asian ethnic groups. Br J Nutr 2015; 113: 1228-1236

[49] Henson J, Davies M], Bodicoat DH et al. Breaking up prolonged sitting with standing or walking attenuates the postprandial metabolic response in postmenopausal women: a randomized acute study. Diabetes Care 2016; 39: 130-138

[50] McCarthy M, Edwardson CL, Davies M] et al. Fitness moderates glycemic responses to sitting and light activity breaks. Med Sci Sports Exerc 2017; 49: 2216-2222

[51] McCarthy M, Edwardson CL, Davies M] et al. Breaking up sedentary time with seated upper body activity can regulate metabolic health in obese high-risk adults: a randomized crossover trial. Diabetes Obes Metab 2017; 19: 1732-1739
[52] Leroith D. $\beta$-cell dysfunction and insulin resistance in type 2 diabetes: role of metabolic and genetic abnormalities. Am J Med 2002; 113: 3S-11S

[53] Jitrapakdee S, Wutthisathapornchai A, Wallace J et al. Regulation of insulin secretion: role of mitochondrial signalling. Diabetologia 2010; 53: 1019-1032

[54] Del Prato S. Loss of early insulin secretion leads to postprandial hyperglycaemia. Diabetologia 2003; 46: M2-M8

[55] Yajnik CS, Lubree HG, Rege SS et al. Adiposity and hyperinsulinemia in Indians are present at birth. J Clin Endocrinol Metab 2002; 87: 5575-5580

[56] Ehtisham S, Crabtree N, Clark P et al. Ethnic differences in insulin resistance and body composition in United Kingdom adolescents. J Clin Endocrinol Metab 2005; 90: 3963-3969

[57] Forouhi NG, Jenkinson G, Thomas EL et al. Relation of triglyceride stores in skeletal muscle cells to central obesity and insulin sensitivity in European and South Asian men. Diabetologia 1999; 42: 932-935

[58] Lear SA, Kohli S, Bondy GP et al. Ethnic variation in fat and lean body mass and the association with insulin resistance. J Clin Endocrinol Metab 2009; 94: 4696-4702

[59] Mente A, Razak F, Blankenberg S et al. Ethnic variation in adiponectin and leptin levels and their association with adiposity and insulin resistance. Diabetes Care 2010; 33: 1629-1634

[60] Torréns Jl, Skurnick J, Davidow AL et al. Ethnic differences in insulin sensitivity and $\beta$-cell function in premenopausal or early perimenopausal women without diabetes: the Study of Women's Health Across the Nation (SWAN). Diabetes Care 2004; 27: 354-361

[61] Sulistyoningrum DC, Gasevic D, Lear SA et al. Total and high molecular weight adiponectin and ethnic-specific differences in adiposity and insulin resistance: a cross-sectional study. Cardiovasc Diabetol 2013; 12: 170

[62] Ralston JC, Zulyniak MA, Nielsen DE et al. Ethnic- and sex-specific associations between plasma fatty acids and markers of insulin resistance in healthy young adults. Nutr Metab 2013; 10: 42

[63] Lillioja S, Nyomba B, Saad MF et al. Exaggerated early insulin release and insulin resistance in a diabetes-prone population: a metabolic comparison of Pima Indians and Caucasians. J Clin Endocrinol Metab 1991; 73: 866-876

[64] Raygor V, Abbasi F, Lazzeroni LC et al. Impact of race/ethnicity on insulin resistance and hypertriglyceridaemia. Diabetes Vasc Dis Res 2019; 16: 153-159

[65] Fukushima M, Usami M, Ikeda M et al. Insulin secretion and insulin sensitivity at different stages of glucose tolerance: a cross-sectional study of Japanese type 2 diabetes. Metabolism 2004; 53: 831-835

[66] Matsuda M, DeFronzo RA. Insulin sensitivity indices obtained from oral glucose tolerance testing: comparison with the euglycemic insulin clamp. Diabetes Care 1999; 22: 1462-1470

[67] Kuroe A, Fukushima M, Usami M et al. Impaired $\beta$-cell function and insulin sensitivity in Japanese subjects with normal glucose tolerance. Diabetes Res Clin Pract 2003; 59: 71-77

[68] Nakanishi S, Okubo M, Yoneda M et al. A comparison between Japanese-Americans living in Hawaii and Los Angeles and native Japanese: the impact of lifestyle westernization on diabetes mellitus. Biomed Pharmacother 2004; 58: 571-577

[69] Gao H, Salim A, Lee J et al. Can body fat distribution, adiponectin levels and inflammation explain differences in insulin resistance between ethnic Chinese, Malays and Asian Indians. Int J Obes 2012; 36: 1086-1093

[70] Tan VMH, Lee YS, Venkataraman $\mathrm{K}$ et al. Ethnic differences in insulin sensitivity and beta-cell function among Asian men. Nutr Diabetes 2015; 5: e173 
[71] Saad MF, Knowler WC, Pettitt D] et al. A two-step model for development of non-insulin-dependent diabetes. Am J Med 1991; 90: 229-235

[72] Yabe $D$, Seino $Y$, Fukushima $M$ et al. $\beta$ cell dysfunction versus insulin resistance in the pathogenesis of type 2 diabetes in East Asians. Curr Diab Rep 2015; 15: 602

[73] Lear SA, Humphries KH, Kohli S et al. The use of BMI and waist circumference as surrogates of body fat differs by ethnicity. Obesity 2007; 15: 2817-2824

[74] Lear SA, Humphries KH, Kohli S et al. Visceral adipose tissue accumulation differs according to ethnic background: results of the Multicultural Community Health Assessment Trial (M-CHAT). Am J Clin Nutr 2007; 86: 353-359

[75] Anand SS, Tarnopolsky MA, Rashid S et al. Adipocyte hypertrophy, fatty liver and metabolic risk factors in South Asians: the Molecular Study Of Health and Risk in Ethnic Groups (mol-SHARE). PLoS One 2011; 6: e22112

[76] Marathe CS, Bound M, Lange $\mathrm{K}$ et al. Ethnic disparities in insulin and glucose-dependent insulinotropic peptide (GIP) responses to intraduodenal glucose in health. Acta Diabetol 2015; 52: 817-819

[77] Korn ED. Clearing factor, a heparin-activated lipoprotein lipase. I. Isolation and characterization of the enzyme from normal rat heart. Biol Chem 1955; 215: 1-14

[78] Korn ED. Clearing factor, a heparin-activated lipoprotein lipase. II. Substrate specificity and activation of coconut oil. J Biol Chem 1955; 215: $15-26$

[79] Bergeron J, Couillard C, Després JP et al. Race differences in the response of postheparin plasma lipoprotein lipase and hepatic lipase activities to endurance exercise training in men: results from the HERITAGE Family Study. Atherosclerosis 2001; 159: 399-406

[80] Jeppesen J, Hollenbeck CB, Zhou MY et al. Relation between insulin resistance, hyperinsulinemia, postheparin plasma lipoprotein lipase activity, and postprandial lipemia. Arterioscler Thromb Vasc Biol 1995; 15: 320-324

[81] Kiens B, Lithell H, Mikines KJ et al. Effects of insulin and exercise on muscle lipoprotein lipase activity in man and its relation to insulin action. J Clin Invest 1989; 84: 1124-1129

[82] Seip RL, Angelopoulos T], Semenkovich CF. Exercise induces human lipoprotein lipase gene expression in skeletal muscle but not adipose tissue. Am J Physiol 1995; 268: E229-E236

[83] Després JP, Couillard C, Gagnon J et al. Race, visceral adipose tissue, plasma lipids, and lipoprotein lipase activity in men and women: the Health, Risk Factors, Exercise Training, and Genetics (HERITAGE) family study. Arterioscler Thromb Vasc Biol 2000; 20: 1932-1938

[84] Deo RC, Reich D, Tandon A et al. Genetic differences between the determinants of lipid profile phenotypes in African and European Americans: the Jackson Heart Study. PLoS Genet 2009; 5: e1000342

[85] Talmud PJ, Hall S, Holleran S et al. LPL promoter -93T/G transition influences fasting and postprandial plasma triglycerides response in African-Americans and Hispanics. J Lipid Res 1998; 39: 1189-1196

[86] Ehrenborg E, Clee SM, Pimstone SN et al. Ethnic variation and in vivo effects of the $-93 \mathrm{t} \rightarrow \mathrm{g}$ promoter variant in the lipoprotein lipase gene. Arterioscler Thromb Vasc Biol 1997; 17: 2672-2678

[87] Hall S, Chu G, Miller $G$ et al. A common mutation in the lipoprotein lipase gene promoter, $-93 \mathrm{~T} / \mathrm{G}$, is associated with lower plasma triglyceride levels and increased promoter activity in vitro. Arterioscler Thromb Vasc Biol 1997; 17: 1969-1976

[88] Hall S, Talmud PJ, Cook DG et al. Frequency and allelic association of common variants in the lipoprotein lipase gene in different ethnic groups: the Wandsworth Heart and Stroke Study. Genet Epidemiol 2000; 18: 203-216
89] Mailly F, Tugrul Y, Reymer PWA et al. A common variant in the gene for lipoprotein lipase (Asp9 $\rightarrow$ Asn). Functional implications and prevalence in normal and hyperlipidemic subjects. Arterioscler Thromb Vasc Biol 1995; 15: 468-478

[90] Palacio Rojas M, Prieto C, Bermúdez V et al. Dyslipidemia: genetics, lipoprotein lipase and HindIII polymorphism. F1000Res 2017; 6: 2073

[91] Ukkola O, Garenc C, Pérusse L et al. Genetic variation at the lipoprotein lipase locus and plasma lipoprotein and insulin levels in the Québec Family Study. Atherosclerosis 2001; 158: 199-206

[92] Wittrup HH, Andersen RV, Tybjærg-hansen A et al. Combined analysis of six lipoprotein lipase genetic variants on triglycerides, high-density lipoprotein, and ischemic heart disease: cross-sectional, prospective, and case-control studies from the Copenhagen City Heart Study. J Clin Endocrinol Metab 2006; 91: 1438-1445

[93] Bruce CR, Anderson M], Carey AL et al. Muscle oxidative capacity is a better predictor of insulin sensitivity than lipid status. J Clin Endocrinol Metab 2003; 88: 5444-5451

[94] Nyholm B, Nielsen MF, Kristensen K et al. Evidence of increased visceral obesity and reduced physical fitness in healthy insulin-resistant first-degree relatives of type 2 diabetic patients. Eur J Endocrinol 2004; 150: 207-214

[95] Goodpaster BH, Brown NF. Skeletal muscle lipid and its association with insulin resistance: what is the role for exercise? Exerc Sport Sci Rev 2005; 33: 150-154

[96] Nair KS, Bigelow ML, Asmann YW et al. Asian Indians have enhanced skeletal muscle mitochondrial capacity to produce ATP in association with severe insulin resistance. Diabetes 2008; 57: 1166-1175

[97] Murphy C, Kanaganayagam GS, jiang B et al. Vascular dysfunction and reduced circulating endothelial progenitor cells in young healthy UK South Asian men. Arterioscler Thromb Vasc Biol 2007; 27: 936-942

[98] Cubbon RM, Murgatroyd SR, Ferguson C et al. Human exercise-induced circulating progenitor cell mobilization is nitric oxide-dependent and is blunted in South Asian men. Arterioscler Thromb Vasc Biol 2010; 30: 878-884

[99] Williams C], Williams MG, Eynon $\mathrm{N}$ et al. Genes to predict VO2max trainability: A systematic review. BMC Genomics 2017; 18: 831

[100] Nagayama C, Burns SF, Stensel D] et al. Effects of a single bout of walking on postprandial triglycerides in men of Chinese, European and Japanese descent: a multisite randomised crossover trial. BM] Open Sport Exerc Med 2020; 6: e000928

[101] National Institute of Health and Nutrition. The National Health and Nutrition Survey in Japan: Annual Changes in Primary Health Indicators; Available from: https://www.nibiohn.go.jp/eiken/ kenkounippon21/en/eiyouchousa/. Accessed: 12 May 2021

[102] Ministry of Health. National Health Survey 2010 Singapore. 2010. Available from: https://www.moh.gov.sg/docs/librariesprovider5/ resources-statistics/reports/nhs2010---low-res.pdf. Accessed: 12 May 2021

[103] Guthold R, Stevens GA, Riley LM et al. Worldwide trends in insufficient physical activity from 2001 to 2016: a pooled analysis of 358 population-based surveys with 1.9 million participants. Lancet Glob Health 2018; 6: e1077-e1086

[104] Harriss D], Macsween A, Atkinson G. Ethical standards in sport and exercise science research: 2020 update. Int J Sports Med 2019; 40: 813-817 